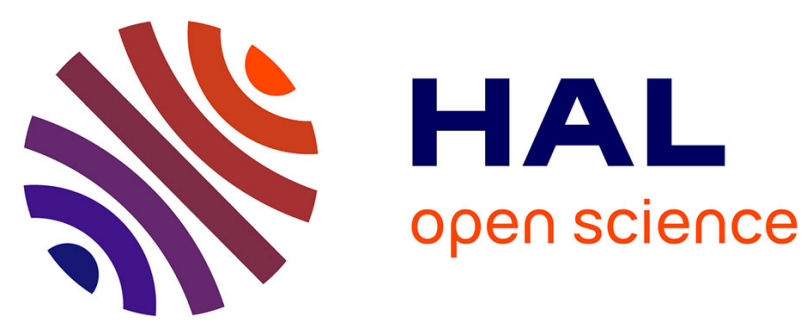

\title{
Sodium Site Exchange and Migration in a Polar Stuffed-Cristobalite Framework Structure
}

Alberto J Fernández-Carrión, Aydar Rakhmatullin, Li Yang, Michael J Pitcher, Dominique Massiot, Florence Porcher, Mathieu Allix, Xiaojun Kuang

\section{- To cite this version:}

Alberto J Fernández-Carrión, Aydar Rakhmatullin, Li Yang, Michael J Pitcher, Dominique Massiot, et al.. Sodium Site Exchange and Migration in a Polar Stuffed-Cristobalite Framework Structure. Inorganic Chemistry, 2021, 60 (7), pp.4322-4331. 10.1021/acs.inorgchem.1c00319 . hal-03190138

\section{HAL Id: hal-03190138 \\ https://hal.science/hal-03190138}

Submitted on 6 Apr 2021

HAL is a multi-disciplinary open access archive for the deposit and dissemination of scientific research documents, whether they are published or not. The documents may come from teaching and research institutions in France or abroad, or from public or private research centers.
L'archive ouverte pluridisciplinaire HAL, est destinée au dépôt et à la diffusion de documents scientifiques de niveau recherche, publiés ou non, émanant des établissements d'enseignement et de recherche français ou étrangers, des laboratoires publics ou privés. 


\title{
Sodium Site Exchange and Migration in Polar
}

\section{Stuffed Cristobalite Framework Structure}

\author{
Alberto J. Fernández-Carrión ${ }^{a}$, Aydar Rakhmatullin ${ }^{b}$, Li Yang $^{a}$, Michael J. Pitcher ${ }^{b}$, Dominique \\ Massiot $^{b}$, Florence Porcher ${ }^{c}$, Mathieu Allix ${ }^{b}$, Xiaojun Kuang ${ }^{a, d} *$
}

${ }^{a}$ MOE Key Laboratory of New Processing Technology for Nonferrous Metals and Materials, Guangxi Key Laboratory of Optical and Electronic Materials and Devices, College of Materials Science and Engineering, Guilin University of Technology, Guilin 541004, P. R. China.

${ }^{\mathrm{b}}$ CNRS, CEMHTI UPR3079, Univ. Orléans, F-45071 Orléans, France.

${ }^{c}$ Laboratoire Léon Brillouin, CEA Saclay, 91191 Gif Sur Yvette, France.

${ }^{\mathrm{d}}$ College of Chemistry and Bioengineering, Guilin University of Technology, Guilin 541004, P. R. China.
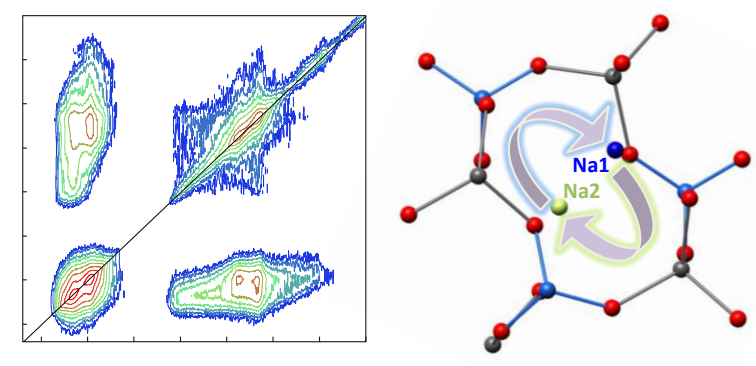

Table of Contents. Two-dimensional exchange ${ }^{23} \mathrm{Na}$ NMR spectroscopy evidences sodium site exchange phenomenon in polar stuffed Cristobalite $o-\mathrm{Na}_{2} \mathrm{MgSiO}_{4}$ which triggers the long-range sodium migration. 


\begin{abstract}
:
The study of ionic dynamics in solids is essential to understand and develop modern energy technologies. Here we study the ionic dynamics of orthorhombic $\mathrm{Na}_{2} \mathrm{MgSiO}_{4}$, an interesting case of a polar stuffed cristobalite-type structure that contains two inequivalent $\mathrm{Na}$ sites within the channels of the magnesium-silicate tetrahedral framework. Its preparation by solid state reaction method favours the presence of $\sim 2 \%$ of $\mathrm{Na}$ vacancies, converting it into pure sodium ionic conductor with an optimized ionic conductivity of $\sim 10^{-5} \mathrm{~S} \mathrm{~cm}^{-1}$ at $200{ }^{\circ} \mathrm{C}$. The macroscopic migration has been characterized through impedance spectroscopy and molecular dynamics simulation which proves the pure sodium ionic character of the compound through hopping between $\mathrm{Na} 1$ and $\mathrm{Na} 2$ sites, forming three-dimensional migration zig-zag shaped paths. Highresolution solid-state ${ }^{23} \mathrm{Na}$ magic MAS-NMR spectroscopy is employed to characterize the local structure and microscopic dynamics of sodium ion transport in $\mathrm{Na}_{2} \mathrm{MgSiO}_{4}$. Remarkably, variable temperature ${ }^{23} \mathrm{Na}$ MAS NMR and two-dimensional exchange spectroscopy evidence for the first time a sodium site exchange phenomenon at room temperature, which further triggers the sodium ionic conduction at elevated temperatures.
\end{abstract}




\section{Introduction}

Ionic migration in solid state materials is a key physical phenomenon in numerous technologically important compounds such as solid state electrolytes used in batteries, ${ }^{1}$ electrochromic displays, ${ }^{2}$ sensors ${ }^{3}$ or solid oxide fuel cells (SOFCs). ${ }^{4}$ It is important to understand the interplay between ionic migration and structural chemistry, which helps improving the ionic conduction and guiding the materials design. Electrochemical impedance measurements (EIS) are frequently used to characterize the macroscopic long-range diffusional migration coupled to molecular dynamic (MD) simulations. ${ }^{5,6}$ Nevertheless, detailed knowledge of the microscopic dynamic processes (set by the distance between neighboring atoms sites, i.e. at atomic and/or molecular scale) underlying ionic conductance is still required in order to fully understand and predict the behavior of ionic conducting materials.

Among the different techniques characterizing solid state inorganic materials at local scale, solid state magic angle spinning nuclear magnetic resonance (MAS NMR) is a powerful tool. It has been widely employed to explore the local environment of certain atoms allowing, for instance, the concrete crystallographic description of unit cells, local structure around defects and so on. The application of this technique has been further enhanced by the possibility to acquire MAS NMR spectra at variable temperatures (VT MAS NMR), ${ }^{7}$ which expands the possibility to study the dynamic processes of mobile species present in solid state ionic conductors as a function of temperature. ${ }^{8}$ Moreover, for materials possessing multiple sites for mobile ions, it enables distinguishing ions moving on inequivalent sites that can lead to multiple possible pathways for diffusion. For this kind of materials, the clearest sign of diffusive dynamics is the merging of spectral peaks, initially assigned to atoms in different structural environments, with increasing temperature. ${ }^{9}$ The information on the ionic dynamics by NMR spectroscopy can be 
further extended using two-dimensional exchange NMR spectroscopy (2D EXSY) ${ }^{10}$ that allows detecting exchange processes between ions on multiple sites during the initial migration stages. These techniques to study the ionic dynamics in solids have been frequently employed for characterizing the dynamics in lithium ion conductors. ${ }^{11,}{ }^{12}$ Nevertheless, studies about the dynamics in $\mathrm{Na}$ ion conductors still remain scarcely explored even when they are potential materials as solid state electrolytes for batteries.

In this study, we investigate the sodium dynamics in stuffed cristobalite $\mathrm{Na}_{2} \mathrm{MgSiO}_{4}$ using EIS and MD simulations coupled to NMR spectroscopy. This compound exhibits a tetrahedral framework based on corner-linked $\left[\mathrm{SiO}_{4}\right]^{4-}$ and $\left[\mathrm{MgO}_{4}\right]^{6-}$ units with two inequivalent sodium sites stuffing the channels formed in the tetrahedral network. It was initially identified as potential sodium ion conductor due to its framework structure, where three-dimensional (3D) conductivity might be expected. ${ }^{13,14}$ Two different polymorphs have been reported at room temperature: firstly Baur synthesized it hydrothermally and described its structure in the nonpolar $P n$ space group $\left(m-\mathrm{Na}_{2} \mathrm{MgSiO}_{4}\right),{ }^{13}$ then Withers et al. ${ }^{15}$ prepared it following a sol-gel route and described its structure by using the polar Pna2 ${ }_{1}$ space group $\left(o-\mathrm{Na}_{2} \mathrm{MgSiO}_{4}\right)$. Both orthorhombic and monoclinic structures contain an ordered $\mathrm{Si} / \mathrm{Mg}$ distribution but differ in the pattern of tetrahedral tilting (Figure 1). Herein we obtain the polar $o-\mathrm{Na}_{2} \mathrm{MgSiO}_{4}$ phase and demonstrate remarkable sodium site exchange at room temperature between the two inequivalent $\mathrm{Na}$ sites, the subsequently triggered sodium migration and its mechanism at elevated temperatures in this polar stuffed cristobalite. 

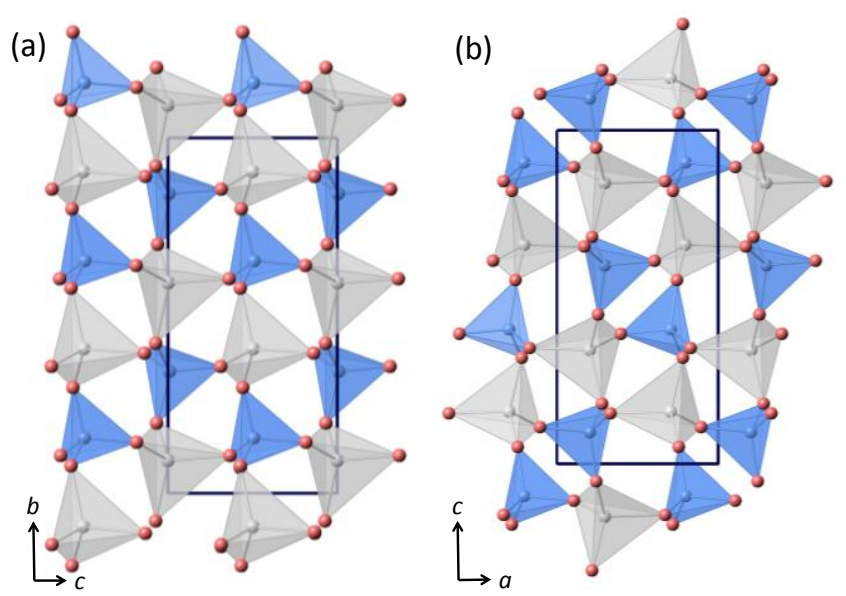

Figure 1. Tetrahedral framework structure comparison between $m-\mathrm{Na}_{2} \mathrm{MgSiO}_{4}$ (a) and $o$ $\mathrm{Na}_{2} \mathrm{MgSiO}_{4}$ (b) as described by Baur (ICSD 15618) and Withers et al. (ICSD 84562), respectively. Shaded blue and grey tetrahedra contain $\mathrm{Si}$ and $\mathrm{Mg}$, respectively. The $\mathrm{O}$ atoms are illustrated by red balls atoms.

\section{Methods}

\subsection{Synthesis}

$\mathrm{Na}_{2} \mathrm{MgSiO}_{4}$ has been synthesized by solid state chemistry route. Starting reagents were high purity $\mathrm{Na}_{2} \mathrm{CO}_{3}\left(99.99 \%\right.$, Aladdin), $\mathrm{MgO}$ (99.8 \%, Aladdin) and $\mathrm{SiO}_{2}$ (99.99\%, Aladdin). Both $\mathrm{Na}_{2} \mathrm{CO}_{3}$ and $\mathrm{MgO}$ were initially dried at $350{ }^{\circ} \mathrm{C}$ and $1000{ }^{\circ} \mathrm{C}$ overnight, respectively. The starting materials were weighed according to the stoichiometry and mixed in ethanol with an agate mortar and pestle. The dried mixtures were pressed under 4 Tons in a $12 \mathrm{~mm}$ diameter cylinder and calcined at $975{ }^{\circ} \mathrm{C}$ for $12 \mathrm{~h}$ for three times with intermediate grindings and pressings. The same batch of $\mathrm{Na}_{2} \mathrm{MgSiO}_{4}$ was used for the subsequent characterization techniques. Additionally, in order to maximize the ionic conductivity while preserving the polar orthorhombic phase, $\mathrm{Na}_{2-2 x} \mathrm{Mg}_{1-x} \mathrm{Si}_{1+x} \mathrm{O}_{4}(x=0.015,0.025)$ compounds were prepared following the same method through substitution of $\mathrm{Mg}$ for $\mathrm{Si}$ to induce sodium vacancies. In order to 
prepare pellets for EIS measurements, the powder was mixed with polyvinyl acetate (PVA) and then sintered at $975^{\circ} \mathrm{C}$.

\subsection{Characterization}

Second-harmonic generation (SHG) measurements were carried out on the powders using the Kurtz-Perry method. ${ }^{16}$ The measurements were performed with a Q-switched Nd:YAG laser at a wavelength of $1064 \mathrm{~nm}$. The intensity of the frequency-doubled output emitted from the samples was collected by a photomultiplier tube and compared to crystalline $\mathrm{KH}_{2} \mathrm{PO}_{4}$ (KDP, serving as reference).

Differential scanning calorimetry (DSC) data was acquired on a PerkinElmer STA 8000 simultaneous analyzer. About $20 \mathrm{mg}$ of $o-\mathrm{Na}_{2} \mathrm{MgSiO}_{4}$ was placed in an $\mathrm{Al}_{2} \mathrm{O}_{3}$ crucible, heated at a rate of $10^{\circ} \mathrm{C} \mathrm{min}-1$ from room temperature to $800{ }^{\circ} \mathrm{C}$, and then cooled to room temperature at the same rate under flowing air.

The identification of the crystalline phases was initially determined by laboratory X-ray powder diffraction (XRD), which were recorded on a Bragg-Brentano D8 Advance Bruker diffractometer $(\mathrm{Cu} \mathrm{K} \alpha$ radiation) equipped with a LynxEye XE detector over an angular range of $10^{\circ}<2 \theta<130^{\circ}$. Variable temperature X-ray diffraction (VT-XRD) data were collected on Panalytical X'Pert PRO powder diffratometer ( $\mathrm{CuK \alpha}$ radiation) equipped with HTK1200N furnace over the $15-65^{\circ} 2 \theta$ range every $50^{\circ}$ Cfrom RT up to $800{ }^{\circ} \mathrm{C}$ using $5^{\circ} \mathrm{C} / \mathrm{min}$ heating and cooling rates, and allowing $3 \mathrm{~min}$ for temperature equilibration before collecting the data for 30 min at each set point.

High-intensity and high-resolution synchrotron X-ray powder diffraction (SPD) data was recorded on the 11-BM diffractometer at the Advanced Photon Source, Argonne National 
Laboratory (USA). For this experiment, a sample of nominal composition $\mathrm{Na}_{2} \mathrm{MgSiO}_{4}$ was used. SPD data was acquired over the $0.5-502 \theta$ range with a 0.001 step size at room temperature.

Constant-wavelength $(\lambda=1.2289 \AA)$ neutron powder diffraction (NPD) data were collected at ambient temperature over the $10-120^{\circ} 2 \theta$ range at $2 \theta$ intervals of $0.05^{\circ}$ on the $3 \mathrm{~T} 2$ diffractometer at LLB-Orphée source (France).

The diffraction patterns were analysed using the Rietveld method implemented in the TopasAcademic software ${ }^{17}$ to identify the corresponding phase and estimate the amount and distribution of $\mathrm{Na}$ content. The bond valence sum calculation for the $\mathrm{Na}-\mathrm{O}, \mathrm{Si}-\mathrm{O}$ and $\mathrm{Mg}-\mathrm{O}$ bonds obtained from Rietveld analysis were calculated according to the following expression ${ }^{18,19}$

$$
\sum v_{i}=\exp \left[\left(R_{i j}-d_{i j}\right) / b\right]
$$

where $v_{i}$ is the bond valence bond between the cation $\mathrm{i}$ and the anion $j, \mathrm{~b}$ is a universal constant (0.37), $d_{i j}$ is the observed bond length and the $R_{i j}$ values have been taken as $1.803,1.693$ and 1.64 $\AA$ for $\mathrm{Na}-\mathrm{O}, \mathrm{Mg}-\mathrm{O}$ and $\mathrm{Si}-\mathrm{O}$ bonds, respectively as defined by Brown and Altermatt. ${ }^{18}$

The compositional homogeneity of the samples was analyzed by SEM and energy-dispersive X-ray spectroscopy (EDS) using a ZEISS Gemini SEM 300 scanning electron microscope (SEM, Germany), equipped with OXFORD EDS analyzer (ULTIM MAX 170, U.K.).

Solid state ${ }^{23} \mathrm{Na}$ and ${ }^{29} \mathrm{Si}$ NMR spectra were obtained using Bruker AVANCE I 400 (9.4 T), AVANCE III HD 750 (17.6 T), and AVANCE NEO 850 (20 T) NMR spectrometers. Chemical shifts were referenced to a $0.1 \mathrm{M} \mathrm{NaCl}$ solution for ${ }^{23} \mathrm{Na}$ and tetramethylsilane (TMS) for ${ }^{29} \mathrm{Si}$. ${ }^{23} \mathrm{Na}$ magic-angle spinning (MAS) NMR spectra were acquired at $17.6 \mathrm{~T}$ and $20 \mathrm{~T}$ using MAS probes from Bruker, with $4 \mathrm{~mm}$ and $1.3 \mathrm{~mm}$ diameter rotors at the spinning rates of $12.5 \mathrm{kHz}$ and $60 \mathrm{kHz}$, respectively. ${ }^{29} \mathrm{Si}$ MAS NMR data were collected using a Bruker AVANCE I 400 (9.4 T) spectrometer with a single pulse experiment while samples were spun at a frequency of 7 
$\mathrm{kHz}$ in $7 \mathrm{~mm}$ Bruker probe. For ${ }^{29} \mathrm{Si} \pi / 2$ pulse width was $5 \mu \mathrm{s}$ with a recycle delay of $7200 \mathrm{~s}$. The NMR parameters (chemical shifts, chemical shift anisotropies, asymmetry parameters, line widths, and quadrupolar parameters) were fitted using the DMfit program. ${ }^{20}$ Spin-lattice relaxation (SLR) times $\left(T_{1}\right)$ were obtained using a saturation recovery pulse sequence and the data were fitted to a stretched exponential of the form

$$
1-\exp \left[-\left(\tau / T_{1}\right)^{\alpha}\right](2)
$$

where $\tau$ are variable delays and $\alpha$ is the stretch exponential coefficient (between 0.85 and 1).

Variable temperature ${ }^{23} \mathrm{Na}$ MAS NMR data (up to $730{ }^{\circ} \mathrm{C}$ ) were acquired on a Bruker AVANCE III $750 \mathrm{MHz}$ NMR spectrometer using the diode laser-heated NMR probe head described previously. ${ }^{21}$ The sample was sandwiched between two layers of ground $\mathrm{KBr}$ which allowed for monitoring of the effective sample temperature through the shift of ${ }^{79} \mathrm{Br}$ resonance signal of $\mathrm{KBr}^{22}$ In the high temperature laser heating setting, the sample is contained in an aluminum nitride container placed in a zirconia rotor and immobilized with two O-rings made from the sodium-containing ceramic that give some secondary signals in the high temperature experiments.

${ }^{23} \mathrm{Na} 2 \mathrm{D}$ exchange spectroscopy (EXSY) experiments were conducted at $17.6 \mathrm{~T}$ in a $4 \mathrm{~mm}$ rotor MAS probe while spinning at $12.5 \mathrm{kHz}$ using the echo compensated EXSY pulse sequence developed by Messinger et al. ${ }^{23}$ The acquisition conditions were as follows: $\pi / 2$ pulse $7.75 \mu$ s, mixing time $100 \mathrm{~ms}$ (1250 and 5000 rotor periods), recycle delay $\left(d_{1}\right) 2 \mathrm{~s}$, with quadrature detection in indirect dimension.

Alternating-current (AC) impedance spectroscopy measurements were performed with a Solartron 1260 frequency response analyzer over a frequency range of $10^{-1}-10^{7} \mathrm{~Hz}$ within the $100-800^{\circ}$ Ctemperature range. Platinum paste was coated on the opposite faces of the pellets 
(80\% relative density) and heat treated at $600{ }^{\circ} \mathrm{C}$ for 30 minutes to burn out the organic components in the paste to form platinum electrodes. The impedance data analysis was carried out through the equivalent circuit fitting using the ZView software. ${ }^{24}$ The activation energies $\left(E_{a}\right)$ for ionic migration were determined from the slope of the conductivity curves by linear fitting of the Arrhenius equation:

$$
\log ()=\log \mathrm{A}-\left(E_{a} / 2.303 \mathrm{R} T\right)
$$

where $A$ is the pre-exponential factor, $R$ is the gas constant, and $T$ is the temperature in Kelvin.

\subsection{Theoretical calculations}

Density functional Theory (DFT) calculations for NMR parameters were performed using the CASTEP DFT code, ${ }^{25}$ employing the gauge including projector augmented wave (GIPAW) NMR calculations ${ }^{26}$ following the methodology previously reported. ${ }^{27}$

The atomistic static-lattice and molecular dynamics (MD) atomistic simulations have been carried out on the basis of the interatomic potential approach employing the General Utility Lattice Program (GULP) program. ${ }^{28,29}$ The Buckingham potential function was employed to describe the interactions between ions with the shell model ${ }^{30}$ to describe the polarizability for the structure modeling of $\mathrm{Na}_{2} \mathrm{MgSiO}_{4}$. A three-body potential term was employed to describe the OSi-O interaction. ${ }^{31}$ The potentials parameters used for the atomistic simulations are summarized in Table S1, ${ }^{31,32}$ and tested well to reproduce the crystal structure of $\mathrm{Na}_{2} \mathrm{MgSiO}_{4}$ (Table S2). The MD simulation for sodium migration in $\mathrm{Na}_{2-2 x} \mathrm{Mg}_{1-x} \mathrm{Si}_{1+x} \mathrm{O}_{4}$ were performed with the DL_POLY ${ }^{33}$ code in the NVT ensemble with a Berendsen ${ }^{34}$ thermostat on a $3 \times 6 \times 5$ supercell model containing 2862 atoms (with the inclusion of the shell model) and having compositions of $\mathrm{Na}_{2} \mathrm{MgSiO}_{4}$ and $\mathrm{Na}_{1.95} \mathrm{Mg}_{0.975} \mathrm{Si}_{1.025} \mathrm{O}_{4}$. The system was equilibrated under a constant pressure of $1 \mathrm{~atm}$ for $100 \mathrm{ps}$, adding up to $1,250,000$ time steps with a time step of 0.08 fs before initiating 
the main MD simulations for 100 ps at specific temperatures within the $600{ }^{\circ} \mathrm{C}$ to $1000{ }^{\circ} \mathrm{C}$ temperature range. The substitutions of $\mathrm{Mg}$ with $\mathrm{Si}$ were randomly distributed in the supercell, resulting in Na vacancies uniformly distributed. The Visual Molecular Dynamic package ${ }^{35}$ was adopted to view the migration pathways of $\mathrm{Na}$ ions, and the data of mean square displacements (MSDs) were exported by using nMoldyn code. ${ }^{36}$ Sodium diffusion coefficients were obtained from the MSDs plots as a function of simulation time through linear fitting.

\section{Results and Discussion}

\subsection{Long range structure.}

The as-prepared $\mathrm{Na}_{2} \mathrm{MgSiO}_{4}$ compound exhibits weak second harmonic generation response $(\sim 0.125 \times \mathrm{KDP}$ at room temperature), confirming a non-centrosymmetric structure. The laboratory XRD pattern of $\mathrm{Na}_{2} \mathrm{MgSiO}_{4}$ can be correctly indexed in the $P n a 2_{1}$ space group with $a \sim 10.89 \AA, b \sim 5.29 \AA, c \sim 7.06 \AA$, similar to the unit cell reported by Withers et al (ICSD 84562). ${ }^{15}$ This indexation was confirmed by high-resolution SPD pattern recorded at the 11BM beam line, with no evidence for symmetry reduction to the maximal non-isomorphic subgroups $P 1 a 1, P n 11$ or $P 112_{1}$. These data revealed a strong and systematic asymmetry in the peak profiles, which is present throughout the pattern and is strongly $h k l$-dependent. In particular, the $h 00$ peaks were found to exhibit substantial asymmetry with long tails towards high angles, whilst $00 l$ exhibited similar tails towards low-angles, but the $0 k 0$ peak were almost completely symmetrical (Figure S1). This is indicative of a complex microstrain with $a$ - and $c$-parameters (which lie orthogonal to the channels in the framework) strained by compression and elongation respectively, with little apparent strain along the $b$-axis (which runs parallel to the channels, Figure 2a). The peak asymmetry was not apparent in the corresponding neutron diffraction pattern, due to the lower resolution of the instrument. The homogeneity of the sample was then 
checked by EDS-SEM analysis which further evidenced a homogeneous distribution of elements at m-scale (see Figure S2) and no segregation of elements could be detected. We performed chemical analysis in different grains giving the average at $\% 46 \pm 1,27 \pm 1,27 \pm 2$ for $\mathrm{Na}, \mathrm{Mg}$ and $\mathrm{Si}$, respectively. Thus, the EDS-SEM data further confirmed that our sample is well reacted as well as the presence of some $\mathrm{Na}$ defect probably arising from $\mathrm{Na}$ volatilization which is commonly reported in the preparation of Na-based ceramics at high temperatures. ${ }^{14,37,38}$
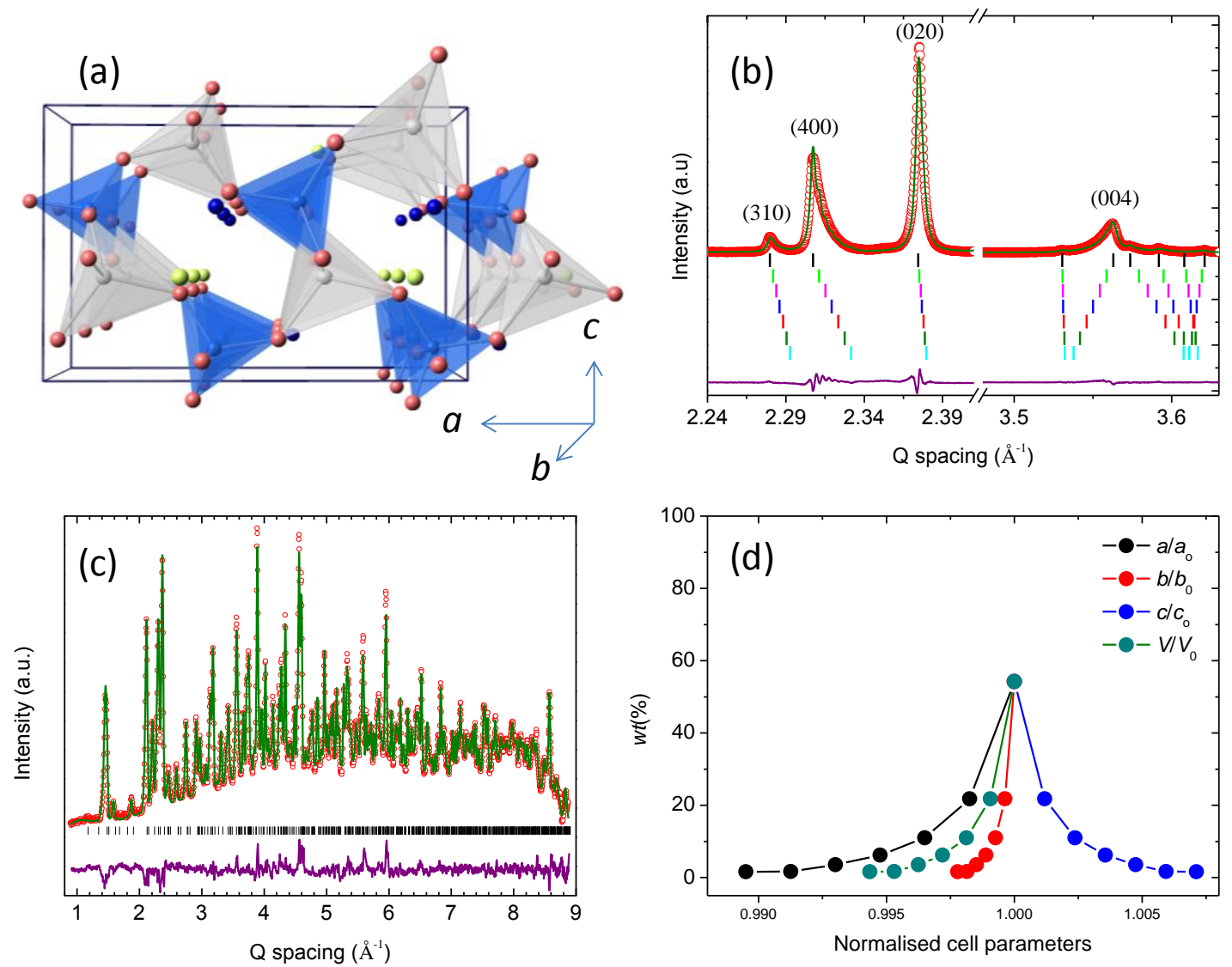

Figure 2. (a) [010] projections of the average $o-\mathrm{Na}_{2} \mathrm{MgSiO}_{4}$ structure emphasizing the tetrahedral framework. Grey and blue colors represent the $\mathrm{Mg}$ and Si atoms, respectively. Navy blue and yellow green colors indicate $\mathrm{Na} 1$ and $\mathrm{Na} 2$, respectively. (b) Representative portion of the Rietveld plots from SPD $\left(R_{\mathrm{wp}}=9.16 \%, R_{\mathrm{p}}=7.11 \%, \chi^{2}=1.01\right)$ and (c) NPD $\left(R_{\mathrm{wp}}=2.61 \%, R_{\mathrm{p}}\right.$ 
$=2.01 \%, \chi^{2}=3.00$ ) data using the multiple cells (seven) based on the Pna2 ${ }_{1}$ structure model. Experimental (circles), fitted (dark green line) and difference curve (purple). The sets of vertical lines correspond to the reflection positions for each one of the seven unit cells of o- $\mathrm{Na}_{2} \mathrm{MgSiO}_{4}$ employed. Overall reliability factors: $R_{\mathrm{wp}}=5.72 \%, R_{\mathrm{p}}=5.26 \%, \chi^{2}=1.44$. d) Normalized refined lattice parameter distribution and unit cell weighting data obtained from SPD-NPD combined refinement.

We then carried out a combined Rietveld refinement using the SPD and NPD datasets. To account for the peak asymmetry in the SPD pattern, we constructed a multiple-unit-cell Rietveld model starting from the published $P n a 2_{1}$ structure of $\mathrm{Na}_{2} \mathrm{MgSiO}_{4}{ }^{15}$ as explained in supplementary Note 1 . Figure $2 \mathrm{~b}$ depicts a representative view of the SPD final refinement $(\mathrm{a}$ general view can be found in Figure S3). Figure 2c presents the final refinement of the NPD pattern. The resulting refined structure represents a weighted average of the seven unit cells, whose refined lattice parameter distribution and weighting is shown in Figure 2d. The final refined composition was $\mathrm{Na}_{1.968(3)} \mathrm{Mg}_{0.968(4)} \mathrm{Si}_{1.032(4)} \mathrm{O}_{4}$, leading to a mechanism in which sodium volatilization induces sodium vacancies that are compensated by Si substitution for $\mathrm{Mg}$ according to $\mathrm{Na}_{2-2 x} \mathrm{Mg}_{1-x} \mathrm{Si}_{1+x} \mathrm{O}_{4}$. The multi-cell refinement results indicate that the sample contains a small sub-micro compositional distribution arising from uncontrollable $\mathrm{Na}$ volatilization that is strongly coupled to an anisotropic local distortion of the crystal structure that shortens/elongates the $a / c$ lattice parameters respectively (see Figure 2d), while the $b$ parameter is only weakly affected because the channels are distributed along this [010] direction (Figure 2a). This is possible because of the high flexibility of the framework structure through the tetrahedral connections even when the $\mathrm{Si} / \mathrm{Mg}$ tetrahedra are quite rigid. ${ }^{39}$ Overall this causes the unit cell volume to be strained towards smaller values, which is consistent with the presence 
of vacancies on the $\mathrm{Na}$ sites as well as the $\mathrm{Si}^{4+}$ substitution for the larger $\mathrm{Mg}^{2+}$. It is worth noting that careful examination of the final refinement of SPD data evidenced a set minor unindexed reflections (Figure S4). Although we could not assign them to any known compound within the $\mathrm{Na}_{2} \mathrm{O}-\mathrm{MgO}-\mathrm{SiO}_{2}$ phase diagram, it is consistent with the proposed mechanism in which sodium vacancies from sodium volatilization are compensated by the substitution of $\mathrm{Si}$ for $\mathrm{Mg}$, which drove the final composition of the sample into a multiple-phase coexistence. The validity of our multiple-unit-cell model was further corroborated with the preparation of two additional nonstoichiometric compounds belonging to the $\mathrm{Na}_{2-2 x} \mathrm{Mg}_{1-x} \mathrm{Si}_{1+x} \mathrm{O}_{4}$ system, i.e. $x=0.015,0.025$ which exhibit the same unit cell parameters evolution (smaller $a$ axis, longer $c$ axis but nearly unchanged $b$ axis and overall unit cell volume reduction, Figure S5a-b).

Table S1-2 gather the refined structural parameters and main bond distances of the main phase. The two inequivalent $\mathrm{Na}$ sites hosted within the channels in the -cristobalite structure exhibits similar number of vacancies $(\sim 1 \%$ and $2 \%$ in $\mathrm{Na} 1$ and $\mathrm{Na} 2$, respectively). Both are coordinated by twelve oxygens, although a careful observation of the $\mathrm{Na}-\mathrm{O}$ bond lengths indicates the presence of five and four nearest oxygen to $\mathrm{Na} 1$ and $\mathrm{Na} 2$ sites, respectively, within $2.31-2.75 \AA$ as first coordination spheres, while the rest are placed further than $3 \AA$. Therefore, considering $\mathrm{Na} 1$ as five coordinated and $\mathrm{Na} 2$ as four coordinated seems reasonable given their respective bond valence sums (BVS) 0.88 and 1.08 close to unit.

\subsection{Short range structure}

${ }^{29}$ Si MAS NMR. The room temperature ${ }^{29}$ Si MAS NMR spectrum (Figure S6) mainly contains one Si site in very symmetrical tetrahedral $\mathrm{Si}(4 \mathrm{Mg})$ environment, confirming an ordered $\mathrm{Si} / \mathrm{Mg}$ distribution in the structure. The value of the ${ }^{29} \mathrm{Si}$ chemical shift, $-69.3 \mathrm{ppm}$, and the full width at half-maximum (FWHM), $76 \mathrm{~Hz}(1.0 \mathrm{ppm})$, are close to those obtained by Withers et al., i.e., - 
$68.9 \mathrm{ppm}$ and FWHM $=1.2 \mathrm{ppm} .{ }^{15}$ In addition, there is another weak resonance around -75.3 ppm. This signal may be attributed to the secondary phase observed by SPD. Nevertheless, we have dismissed it because the relative amount of $\mathrm{Si}$ in different environments is $94 / 6$ according to the ${ }^{29} \mathrm{Si}$ MAS NMR spectrum fit, while the amount of the impurity phase has been estimated as $0.3 w t \%$ from the SPD pattern (calculated from the $A_{020} / A_{\mathrm{i}}$ ratio, being $A_{020}$ the integrated area of the $(020)$ reflection and $A_{\mathrm{i}}$ the integrated area of the unindexed peak at $2 \sim 10.7^{\circ}$ - Figure S4). More likely, the presence of this signal can be assigned to the existence of a $\mathrm{Si}(3 \mathrm{Mg}, 1 \mathrm{Si})$ site as described by Withers et al. for the non-stoichiometric compounds in $\mathrm{Na}_{2-2 x} \mathrm{Mg}_{1-x} \mathrm{Si}_{1+x} \mathrm{O}_{4}$ system (i.e., $-74.9 \mathrm{ppm}) .{ }^{15}$ Moreover, the relative amount of $\mathrm{Si}$ in different environment $(\mathrm{Si}(4 \mathrm{Mg})$ and $\mathrm{Si}(3 \mathrm{Mg}, 1 \mathrm{Si}))$ determined as $94 / 6$ is in reasonably good agreement to the refined composition, 97.8(3)/3.2(3). This further supports that some Si moves inside the Mg tetrahedra to compensate the charge imbalance due to $\mathrm{Na}$ volatilization. Theoretically, $\mathrm{Si}$ substitution for $\mathrm{Mg}$ in the fully ordered structure of $\mathrm{Na}_{2} \mathrm{MgSiO}_{4}$ would have led to formation of $\mathrm{Si}(0 \mathrm{Mg}, 4 \mathrm{Si})$ and $\mathrm{Si}(3 \mathrm{Mg}, 1 \mathrm{Si})$ centers. Nevertheless, the presence of additional environments (e.g. $\mathrm{Si}(0 \mathrm{Mg}, 4 \mathrm{Si}), \mathrm{Si}(1 \mathrm{Mg}, 3 \mathrm{Si})$ or $\mathrm{Si}(2 \mathrm{Mg}, 2 \mathrm{Si}))$ were not detected, which indicates that small amount of Si substitution for $\mathrm{Mg}$ in the ordered $\mathrm{Na}_{2} \mathrm{MgSiO}_{4}$ avoids condensation of $\mathrm{SiO}_{4}$ tetrahedra. This may interrupt locally ordered $\mathrm{Mg}$ and $\mathrm{Si}$ distribution in $\mathrm{Na}_{2} \mathrm{MgSiO}_{4}$, which accounts for the swelling feature on the background of NPD data (Figure 2c).

${ }^{23} \boldsymbol{N a} \boldsymbol{M A S} \boldsymbol{N M R}$. The room temperature ${ }^{23} \mathrm{Na}$ MAS NMR spectrum revealed the presence of two Na sites with relative multiplicities of 1:1 with well-defined quadrupolar line shapes (Figure $3)$, as expected. From the fitted spectrum, the chemical shifts $\left(\delta_{\text {iso }}\right)$ and quadrupolar parameters (quadrupolar constant, $C_{\mathrm{Q}}$ and asymmetry parameter, $\eta_{\mathrm{Q}}$ ) were obtained and the assignment of ${ }^{23} \mathrm{Na}$ resonances to sodium crystallographic sites based on the DFT computations considering the 
$\mathrm{Mg} / \mathrm{Si}$ fully ordered structural model is given in Table 1 . Na1 site exhibits a larger quadrupolar coupling $C_{\mathrm{Q}}(3.3 \mathrm{MHz})$ than that observed for $\mathrm{Na} 2(2.1 \mathrm{MHz})$, confirming the more distorted environment observed from the SPD data refinement (Figure 3).

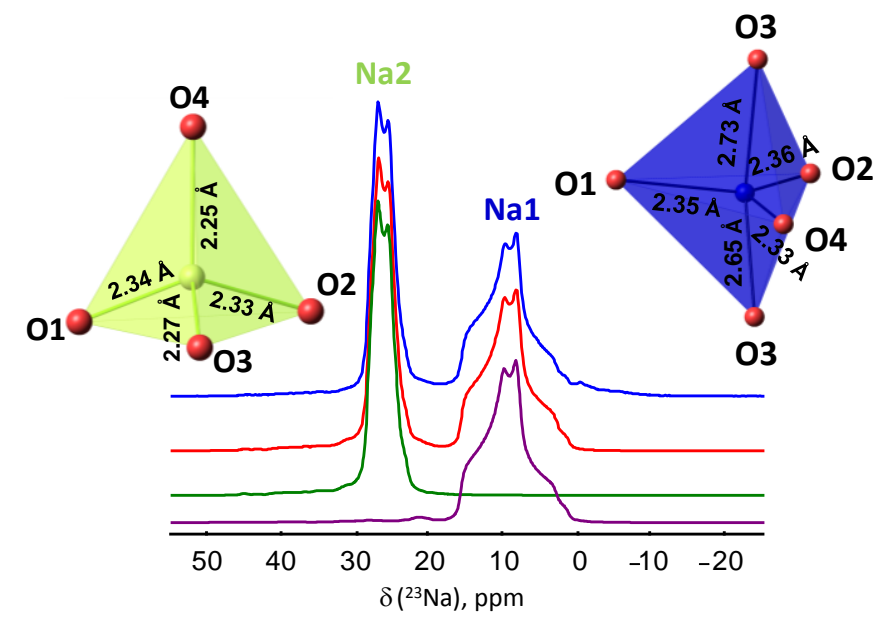

Figure 3. Experimental (blue) and simulated (red) ${ }^{23} \mathrm{Na}$ MAS NMR spectra at $20 \mathrm{~T}$ and $60 \mathrm{kHz}$ recorded at room temperature. The fitting of the individual ${ }^{23} \mathrm{Na}$ resonances at $\mathrm{Na} 1 \mathrm{and} \mathrm{Na} 2$ sites are shown in purple and green, respectively. Inset: Sodium coordination polyhedra in Na1 and $\mathrm{Na} 2$ sites. The bond lengths have been obtained from Rietveld combined refinement on NPDSPD data.

Table $1 .{ }^{23} \mathrm{Na}$ isotropic chemical shifts $\left(\delta_{i s o}\right)$, quadrupolar constants $\left(C_{Q}\right)$, integrated intensity $(I)$ and asymmetry parameters $\left(\eta_{Q}\right)$ obtained from the simulation of the ${ }^{23} \mathrm{Na}$ MAS at $17.6 \mathrm{~T}$ and 20 $\mathrm{T}$ and calculated ${ }^{23} \mathrm{Na}$ NMR parameters (isotropic magnetic shielding constant $\sigma_{\text {iso }}$, chemical shifts $\delta_{\text {isocalc, }}$ quadrupolar constant $\left|C_{Q \text { calc }}\right|$, and asymmetry parameter $\left.\eta_{Q \text { calc }}\right)$ for $o-\mathrm{Na}_{2} \mathrm{MgSiO}_{4}$.

$\begin{array}{ccccccccc}\text { Site } & \begin{array}{c}\boldsymbol{\delta}_{\text {iso }} \\ \mathbf{0 . 2} \mathbf{p p m}\end{array} & \begin{array}{c}\mathbf{C}_{\mathbf{O}} \\ \mathbf{0 . 2} \mathbf{M H z}\end{array} & \boldsymbol{\eta}_{\mathbf{Q}} \pm \mathbf{0 . 1} & \begin{array}{c}\mathbf{I}(\mathbf{\%}) \\ \pm \mathbf{2 \%}\end{array} & \boldsymbol{\sigma}_{\text {iso }} \mathbf{p p m} & \begin{array}{c}\boldsymbol{\delta}_{\text {isocalc }} \\ \mathbf{p p m}\end{array} & \begin{array}{c}\left|\boldsymbol{C}_{\text {Ocalc }}\right| \\ \mathbf{M H z}\end{array} & \boldsymbol{\eta}_{\text {Qcalc }} \\ \mathrm{Na} 1 & 16.0 & 3.3 & 0.74 & 50 & 537.9 & 16.1 & 3.86 & 0.72 \\ \mathrm{Na} 2 & 28.7 & 2.1 & 0.42 & 50 & 521.6 & 29.8 & 2.33 & 0.32\end{array}$

\subsection{Macroscopic ionic migration}


Electrochemical impedance spectroscopy (EIS). The electrical behavior characterization of the sample was undertaken by EIS. At temperatures below $\sim 150 \quad \mathrm{C}$, the spectra exhibit non-well defined shapes in the low frequency range (see Figure S7). Between $\sim 150-400{ }^{\circ} \mathrm{C}$, the spectra consist of one depressed semicircle arc in the high frequency region and one Warburg-type inclined line in the low frequency region with capacitances of $>10^{-8} \mathrm{~F} \cdot \mathrm{cm}^{-1}$ at $10^{-1} \mathrm{~Hz},{ }^{40}$ indicative of ionic conduction. Figure $4 \mathrm{a}$ depicts the complex impedance plot of $\mathrm{Na}_{2} \mathrm{MgSiO}_{4}$ recorded at $154^{\circ} \mathrm{C}$,showing one asymmetric and depressed semicircular arc in high frequency region. In the $C^{\prime}$ vs. $f$ plot two overlapping plateaus can be apparently discerned within $10^{7}-10^{2}$ $\mathrm{Hz}$ region (Figure $4 \mathrm{a}$, inset): the one in $10^{2}-10^{3} \mathrm{~Hz}$ has capacitances $\sim 2 \mathrm{pF} \cdot \mathrm{cm}^{-1}$ and the other one within $10^{5}-10^{6} \mathrm{~Hz}$ has smaller capacitances $\sim 0.5 \mathrm{pF} \cdot \mathrm{cm}^{-1}$. Both capacitance plateaus lie with the bulk responses, ${ }^{40}$ i.e. that the semicircular arc actually comprises two bulk components and may be indicative of the electrical inhomogeneous nature of the as-prepared $\mathrm{Na}_{2} \mathrm{MgSiO}_{4}$, probably due to partial $\mathrm{Na}$ volatilization. Apart from the overlapping bulk response arc and electrode response line, no apparent grain boundary response was observed in the complex impedance plot. Therefore deconvolution of complex impedance plot was performed through equivalent circuit fitting with two bulk and one electrode components, which is shown in Figure S8. The high frequency part of the bulk impedance data is a series combination of one bulk component consisting of $R_{\mathrm{b} 1}, C_{\mathrm{b} 1}, \mathrm{CPE}_{1}$ in parallel and the other bulk component consisting of $R_{\mathrm{b} 2}, C_{b 2}$ in parallel. The fit gives $R_{\mathrm{b} 1} \quad 1.0(1) \times 10^{7} \Omega \cdot \mathrm{cm}, C_{1} \quad 4.3(3) \times 10^{-13} \mathrm{Fem}^{-1}, R_{\mathrm{b} 2}$ $\sim 2.9(2) \times 10^{6} \Omega \cdot \mathrm{cm}$ and $C_{2} \sim 1.9(1) \times 10^{-12} \mathrm{~F} \cdot \mathrm{cm}^{-1}$. It must be indicated that a CPE element is not included for the second element since its values are not meaningful and, indeed, a satisfactory fit was obtained. While increasing the temperature, the bulk response arc disappeared gradually and above $\sim 400{ }^{\circ} \mathrm{C}$ only electrode response was identified. The electrode response recorded at 
$650^{\circ}$ Cdoes not show any evident collapse after changing the atmosphere from pure nitrogen to pure oxygen, in contrast with the typical behavior to partial oxygen pressure exhibited by oxide ion conductors (Figure 4b). ${ }^{5,41-43}$ Moreover, its ionic conductivity is maintained at different $p \mathrm{O}_{2}$ values (Figure 4b-inset). Therefore, the ionic conduction in $o-\mathrm{Na}_{2} \mathrm{MgSiO}_{4}$ arises from sodium cations instead of oxide ions.

Figure $4 \mathrm{c}$ depicts the Arrhenius plots for the bulk conductivities of $o-\mathrm{Na}_{2} \mathrm{MgSiO}_{4}$. It exhibits $\sigma_{\mathrm{b}}$ $\sim 10^{-5} \mathrm{~S} \cdot \mathrm{cm}^{-1}$ at $300{ }^{\circ} \mathrm{C}$, in good agreement with the values reported by Baur ${ }^{13}$ and Shannon, ${ }^{14}$ and at $800{ }^{\circ} \mathrm{C}$ its conductivity reaches $\sim 5 \times 10^{-3} \mathrm{~S} \cdot \mathrm{cm}^{-1}$. Slight curvature was observed on the Arrhenius plot of bulk conductivity: the $E_{\mathrm{a}}$ is $\sim 0.73(1) \mathrm{eV}$ within $100-500{ }^{\circ} \mathrm{C}$ and then decreases at higher temperatures $\left(\sim 0.51(2) \mathrm{eV}\right.$ between $\left.500-800{ }^{\circ} \mathrm{C}\right)$. This evolution cannot be attributed to any structure change, as either VTXRD or DSC data do not evidence any structure rearrangement apart from the enlargement of the unit cell parameters and $\mathrm{Na}-\mathrm{O}$ bonds (Figure S9-S10, respectively). The change of $E_{\mathrm{a}}$ may be related to a local order-disorder transition of sodium vacancies at high temperature, where the sodium ions become progressively more mobile. Such local order-disorder of small amount of sodium vacancies is not enough to change significantly the environments of sodium ion in the structure. Therefore, it is hard to deduce the information on the order-disorder of sodium vacancies from the variable-temperature ${ }^{23} \mathrm{Na}$ MAS NMR data described later. Moreover, the conductivity can be further improved by inducing more sodium vacancies through varying the stoichiometry allowing for the $\mathrm{Mg}$ substitution for $\mathrm{Si}$ in the tetrahedral network according to the $\mathrm{Na}_{2-2 x} \mathrm{Mg}_{1-x} \mathrm{Si}_{1+x} \mathrm{O}_{4}$ formula proposed above and achieves $\sim 10^{-5} \mathrm{~S} \cdot \mathrm{cm}^{-1}$ at $200{ }^{\circ} \mathrm{C}$ for the $o-\mathrm{Na}_{1.95} \mathrm{Mg}_{0.975} \mathrm{Si}_{1.025} \mathrm{O}_{4}$ nominal composition (Figure $4 \mathrm{c}$ ) while conserving the polar $P n a 2_{1}$ structure. 

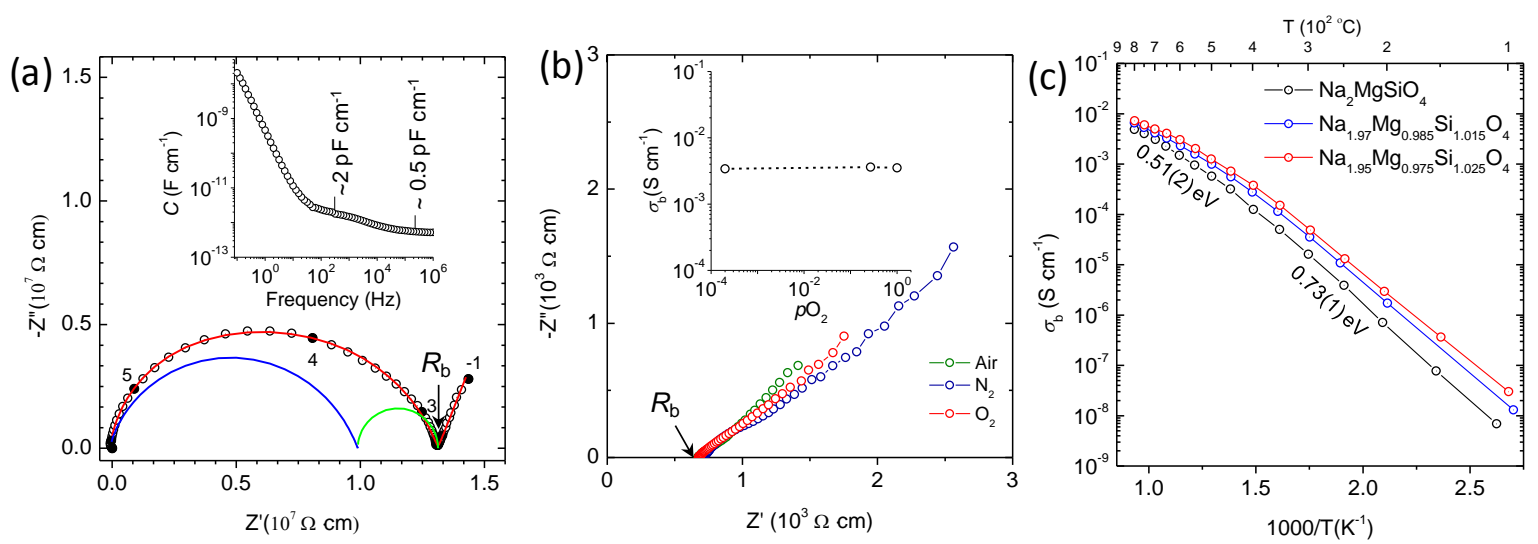

Figure 4. (a) Experimental (open circles) and calculated (red line) complex impedance plot of $o$ $\mathrm{Na}_{2} \mathrm{MgSiO}_{4}$ at $154{ }^{\circ} \mathrm{C}$ in air and its deconvolution to two bulk components (in blue and green lines). The numbers denote the logarithms of the selected frequencies marked by filled circles. The inset shows the capacitance as a function of frequency of $o-\mathrm{Na}_{2} \mathrm{MgSiO}_{4}$ at $154{ }^{\circ} \mathrm{C}$. (b) Complex impedance plots for $o-\mathrm{Na}_{2} \mathrm{MgSiO}_{4}$ at $650{ }^{\circ} \mathrm{C}$ under $\mathrm{N}_{2}$, air and $\mathrm{O}_{2}$. The inset depicts the $p \mathrm{O}_{2}$ dependency of the conductivity of $\mathrm{Na}_{2} \mathrm{MgSiO}_{4}$ at $650{ }^{\circ} \mathrm{C}$. (c) Arrhenius plots of total conductivity for $o-\mathrm{Na}_{2-2 x} \mathrm{Mg}_{x} \mathrm{Si}_{1+x} \mathrm{O}_{4}(x=0,0.015,0.025)$ compositions.

MD simulation. Atomistic static lattice and MD simulations were carried out on the basis of the interatomic potential method for both $o-\mathrm{Na}_{1.95} \mathrm{Mg}_{0.975} \mathrm{Si}_{1.025} \mathrm{O}_{4}$ and $o-\mathrm{Na}_{2} \mathrm{MgSiO}_{4}$ nominal compositions. Figure 5a shows the calculated $\mathrm{MSD}$ values of $\mathrm{Na}, \mathrm{Mg}, \mathrm{Si}$ and $\mathrm{O}$ atoms in $o^{-}$ $\mathrm{Na}_{1.95} \mathrm{Mg}_{0.975} \mathrm{Si}_{1.025} \mathrm{O}_{4}$ obtained at $1000{ }^{\circ} \mathrm{C}$ (generally higher temperatures than the experimental ones are required for the simulations to observe the long-range migration paths within the limited simulated time $100 \mathrm{ps}$ ). Only $\mathrm{Na}$ ions migrate through the structure; $\mathrm{Mg}, \mathrm{Si}$ and $\mathrm{O}$ ions vibrate slightly around their lattice positions without long-range migration, in good agreement with the sodium ionic conduction character revealed by impedance spectroscopy. The sodium diffusion coefficients, calculated from the MSD values of $\mathrm{Na}$ ions, fall in the range of $\sim 10^{-8}-10^{-6} \mathrm{~cm}^{2} \cdot \mathrm{s}^{-1}$ within the $700-1300{ }^{\circ} \mathrm{C}$ temperature range (Figure S11) and the calculated $E_{\mathrm{a}}$ obtained from the 
Arrhenius plot of the sodium diffusion coefficients is $0.69(2) \mathrm{eV}$, which is between the experimental values in the high $(0.73(1) \mathrm{eV})$ and low $(0.51(2) \mathrm{eV})$ temperature ranges. The streaming and overlapping of positions of sodium ions originally at Na1 and Na2 sites in their scatter plots (Figure 5b), together with their MSD values suggest that both $\mathrm{Na}$ sites are involved in, and equally contribute to the sodium ion migration mainly through hopping between Na1 and $\mathrm{Na} 2$ sites, forming three-dimensional migration zig-zag shaped paths. For comparison, the MSD values for $\mathrm{Na}$ ions in $\mathrm{Na}_{2} \mathrm{MgSiO}_{4}$ (red dashed line in Figure 5a), i.e. free of vacancies, are remarkably lower than those calculated for $\mathrm{Na}_{1.95} \mathrm{Mg}_{0.975} \mathrm{Si}_{1.025} \mathrm{O}_{4}$ at the same temperature. This further supports that the presence of $\mathrm{Na}$ vacancies is strictly necessary to observe ionic conductivity in $\mathrm{Na}_{2} \mathrm{MgSiO}_{4}$. 

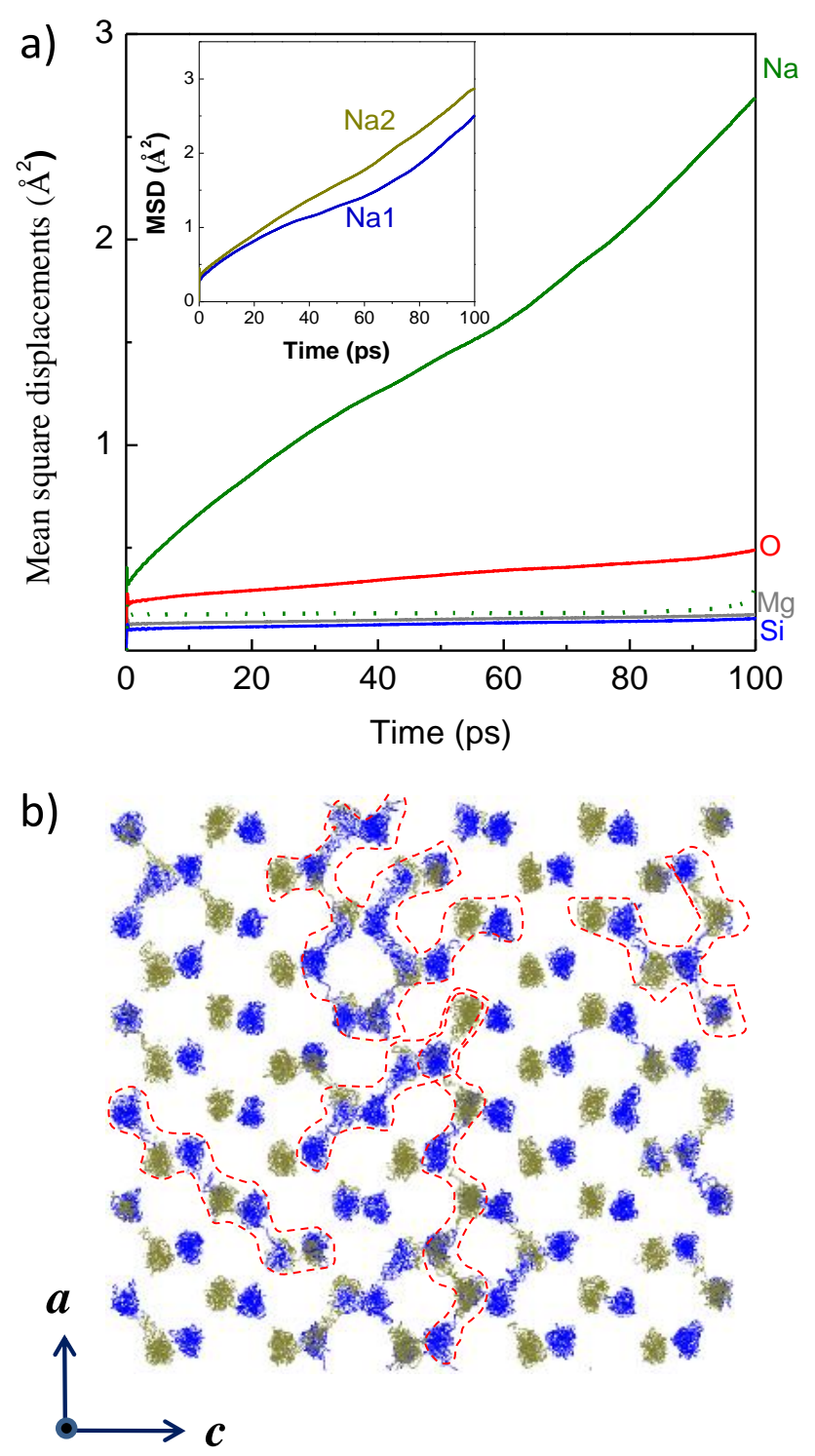

Figure 5. (a) MSD values of $\mathrm{Na}, \mathrm{Mg}$, $\mathrm{Si}$ and $\mathrm{O}$ atoms in $\mathrm{Na}_{1.95} \mathrm{Mg}_{0.975} \mathrm{Si}_{1.025} \mathrm{O}_{4}$ as a function of time from the MD simulations at $1000^{\circ} \mathrm{C}$. The inset depicts the MSD values of Na1 and Na2 atoms. Green dashed line indicates the MSD for $\mathrm{Na}$ in vacancy-free $\mathrm{Na}_{2} \mathrm{MgSiO}_{4}$ compound at $100{ }^{\circ} \mathrm{C}$. (b) Scatter plots of sodium ion positions showing the diffusion paths consisting of both $\mathrm{Na} 1$ and $\mathrm{Na} 2$ sites at $1000{ }^{\circ} \mathrm{C}$ (marked by dashes lines) from MD simulations. Blue and greenish-olive dots denote sodium ions originally placed at $\mathrm{Na} 1$ and $\mathrm{Na} 2$ sites respectively. 


\subsection{Microscopic ionic migration.}

VT ${ }^{23}$ Na MAS NMR spectroscopy. Since the pure sodium ionic conduction nature is demonstrated in $o-\mathrm{Na}_{2} \mathrm{MgSiO}_{4}$, the sodium migration dynamics at local scale was monitored by VT ${ }^{23} \mathrm{Na}$ MAS NMR spectroscopy. As aforementioned, the spectrum of $o-\mathrm{Na}_{2} \mathrm{MgSiO}_{4}$ recorded under a magnetic field of $17.6 \mathrm{~T}$ and spinning at $5 \mathrm{kHz}$ exhibits two well-separated quadrupolar lines expressing second order line shapes. It is worth mentioning that when MAS NMR measurements were performed at room temperature, and without temperature regulation, the actual sample temperatures were $49 \pm 2{ }^{\circ} \mathrm{C}$ at $5 \mathrm{kHz}\left(7 \mathrm{~mm}\right.$ rotor) MAS and $52 \pm 2{ }^{\circ} \mathrm{C}$ at $12.5 \mathrm{kHz}$ (4 mm rotor) due to frictional heating. Considering the 1D experiments (Figure 6a), we observed that the temperature increase from $49^{\circ} \mathrm{C}$ up to $730^{\circ} \mathrm{C}$ first led to the collapse of the quadrupolar line shapes merging to a single broad spectrum at $175-200{ }^{\circ} \mathrm{C}$ that then sharpened into an averaged line up to $730^{\circ} \mathrm{C}$. This behavior is closely related to what was observed for nepheline (a trydimite-type framework) at $500{ }^{\circ} \mathrm{C}$ and it is indicative of an ion exchange process. ${ }^{9,44} \mathrm{As}$ indicated by the VT-XRD data, this tendency cannot be attributed to any structure change within the analyzed temperature range. We have estimated the activation energy for Na migration from ${ }^{23} \mathrm{Na}$ SLR time measurements $\left(T_{1}\right)$ (Figure S12). The linear slope indicates an $E_{\mathrm{a}}=0.321 \mathrm{eV}$ for fluctuations causing relaxation, which is much smaller than that obtained from conductivity measurements $(0.51(2)-0.73(1) \mathrm{eV})$, probably because that NMR relaxation is occurring not only through cationic motion required for diffusion and conductivity, but also via local fluctuation of $\mathrm{Na}$ environment (via local ion hopping back and forth between sites and/or by motion of nearby defects). This may lead to lower activation energies than those needed for through-going (longrange) ionic diffusion alone. ${ }^{11,}{ }^{47-49}$ It is worth noting that both techniques tends to reflect different averaging of the underlying distribution of dynamic processes and it is not surprising to 
observe such a mismatch. For instance, similar phenomenon of lower activation energy observed by NMR than those needed for the longer-range sodium ionic diffusion was also noticed in the glassy phase from the sodium-doped $\mathrm{SrSiO}_{3}$ compositions ${ }^{45}$ or other crystalline sodium-based materials such as $\mathrm{Na}_{2} \mathrm{~B}_{10} \mathrm{H}_{10}{ }^{46}$ or $\mathrm{Na}_{3} \mathrm{InCl}_{6}{ }^{47}$ Therefore the lower activation energy observed by NMR may indicate that local hopping mechanism different from the long-range migration takes place in the sample.

${ }^{23} \mathrm{Na}$ 2D EXSY experiments. In order to better understand the dynamics of sodium mobility in the material at moderate temperature and before the merging of quadrupolar line-shapes, we performed ${ }^{23} \mathrm{Na} 2 \mathrm{D}$ EXSY experiments at $52{ }^{\circ} \mathrm{C}$ and $100^{\circ} \mathrm{C}$. The EXSY experiments (Figure 6b) allow evidencing slow ionic jumps between the ${ }^{23} \mathrm{Na}$ crystallographic sites at the time scale of hundred of ms exchange or mixing time. Non-exchanged $\mathrm{Na}$ atoms do not change frequency during the mixing time but they sign on the diagonal which is homogeneously broadened by spin-spin relaxation $\left(T_{2}\right)$. Na atoms exchanging with a neighboring site will sign as off-diagonal (direct exchange between different structural positions) or on-diagonal cross-peaks (relayed exchange). Thanks to the specific line shapes of the cross-peaks correlating two second order broadened line-shapes, we implemented a simulation of the different components in DMfit (available from version \#20200728 available on request) and to retrieve their respective contributions (integrals of diagonal and cross peaks). ${ }^{20}$ At $52{ }^{\circ} \mathrm{C}$ and $100 \mathrm{~ms}$ exchange we observe $83 \%$ of non-exchanged $\mathrm{Na}$ atoms, $17 \%$ of exchange between Na1 and Na2 sites and negligible self exchange; at $100{ }^{\circ} \mathrm{C}$ and $100 \mathrm{~ms}$ exchange, we observe at $23 \%$ of non-exchanged $\mathrm{Na}$ atoms, $48 \%$ of exchange between $\mathrm{Na} 1$ and $\mathrm{Na} 2$ sites and $28 \%$ self exchange (Table S5). 

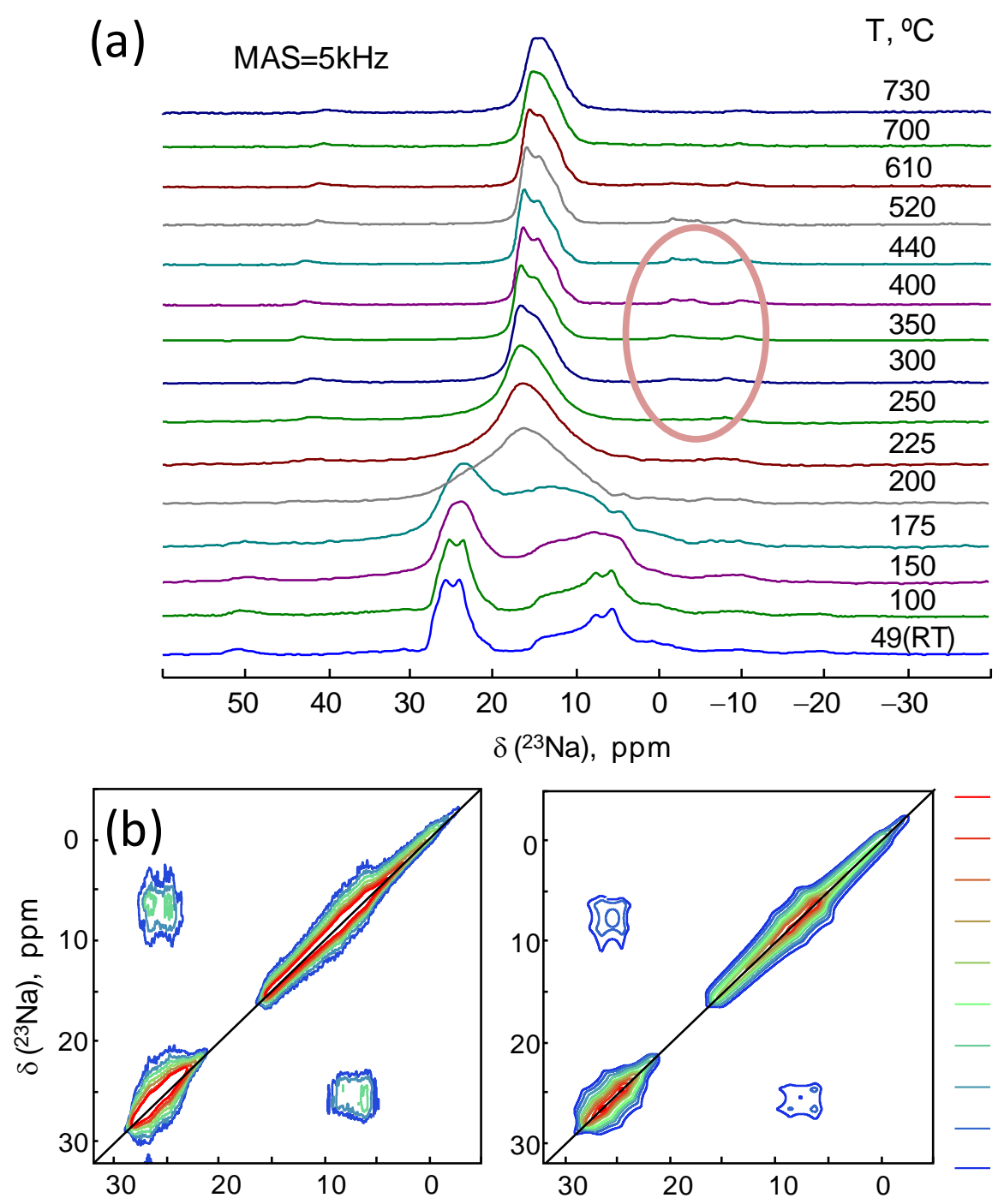

$45.0 \%$

- $32.1 \%$

- $33 . \theta \%$

- $18.4 \%$

$-11.7 \%$

$8: 4 \%$

- $6.0 \%$

$-4.3 \%$

- $3.0 \%$
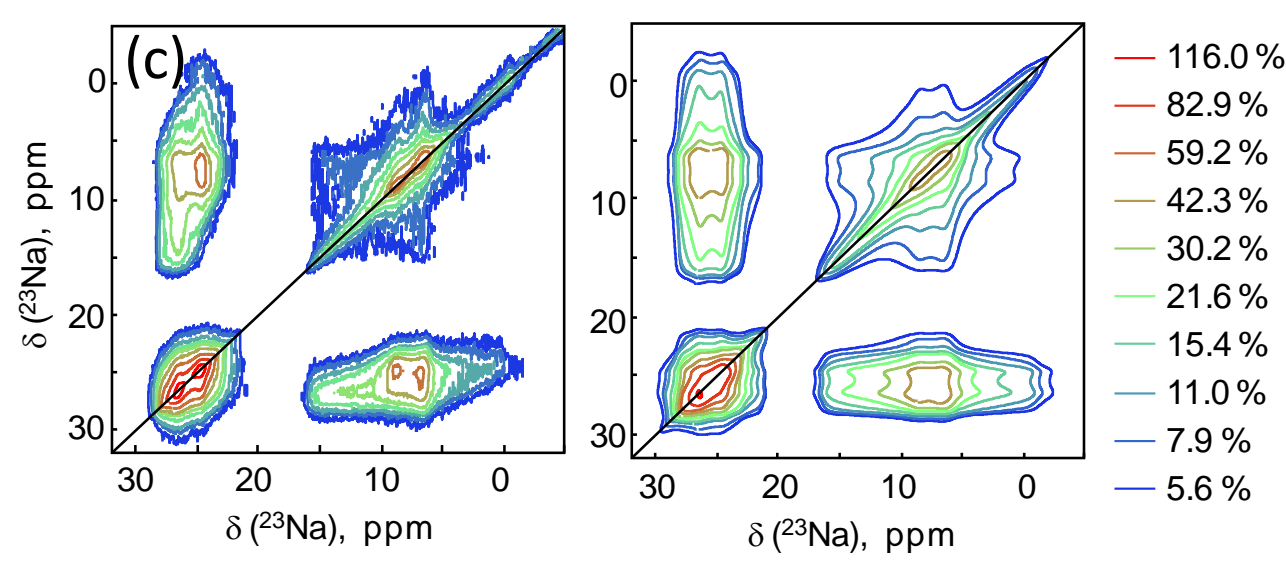

Figure 6. (a) ${ }^{23} \mathrm{Na}$ NMR spectra recorded at $17.6 \mathrm{~T}$ and MAS $5 \mathrm{kHz}$ as a function of temperature. The weak ${ }^{23} \mathrm{Na}$ signals between -5 and $-2 \mathrm{ppm}$ (red circle) arise from the ceramic O-rings used 
to fix the AlN sample holder in place within the zirconia rotor. (b-c) ${ }^{23} \mathrm{Na} 2 \mathrm{D}$ EXSY NMR spectra (left) obtained with $100 \mathrm{~ms}$ mixing time, (b) at $52{ }^{\circ} \mathrm{C}$; (c) at $100{ }^{\circ} \mathrm{C}$ and their fitting results (right).

\subsection{Global sodium migration mechanism in $o-\mathrm{Na}_{2} \mathrm{MgSiO}_{4}$}

According to our data covering the sodium dynamics from macroscopic to microscopic range, an atomistic point of view of the $\mathrm{Na}$ migration can be understood as follows. Four Na1 atoms located in the second coordination sphere of the $\mathrm{Na} 2$ atom and also four $\mathrm{Na} 2$ atoms are placed in the second coordination sphere of the Nal atom. Since the distances between two different sodium sites $(3.12 ; 3.23 ; 3.30 ; 3.36 \AA)$ are shorter than the distances between the same sites (from 4.77 up to $5.61 \AA$ ), we only observe exchange between $\mathrm{Na} 1$ and $\mathrm{Na} 2$ sites in the ${ }^{23} \mathrm{Na}$ EXSY NMR spectrum at $52{ }^{\circ} \mathrm{C}$ (this step is illustrated in Figure 7a). Upon slight heating $\left(100^{\circ} \mathrm{G}\right.$, the sodium atoms start to migrate-diffuse within and between the channels of the magnesium-silicate framework. Then, with a further increase in temperature, the movement of atoms becomes very fast and we cannot distinguish these two states anymore on the NMR timescale as inferred from ${ }^{23} \mathrm{Na}$ EXSY NMR data and the long range diffusion of sodium atoms takes place though the 3D framework of the structure mainly along the paths composed of alternate $\mathrm{Na} 1$ and $\mathrm{Na} 2$ sites, as exemplified in Fig $7 \mathrm{~b}$. 


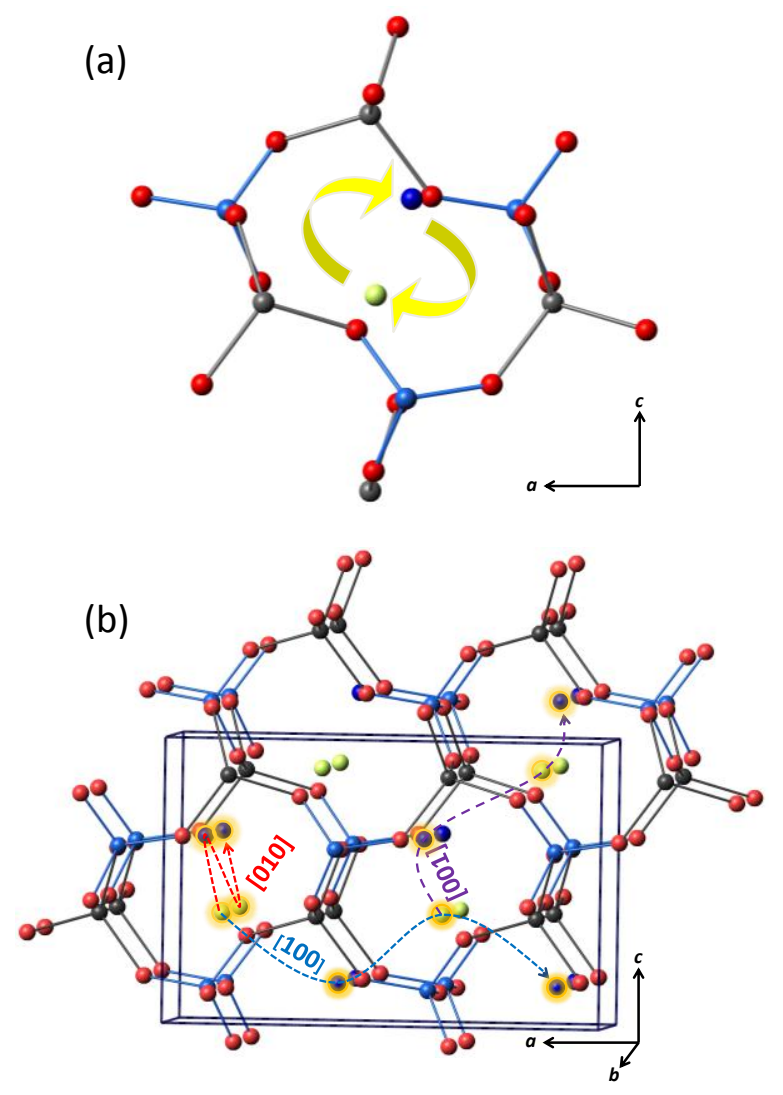

Figure 7. (a) $<010>$ view of the sodium site exchange at low temperatures. Si, Mg, Na1 and Na2 are represented as blue, grey, navy blue and greenish spheres, respectively. (b) $<010>$ view of $\mathrm{Na}_{2} \mathrm{MgSiO}_{4}$ refined structure emphasizing the voids along (010) direction. The macroscopic $\mathrm{Na}$ migration at high temperatures along the [100] (blue), [010] (red) and [001] (purple) directions are indicated. The interconnected $\mathrm{Na}$ atoms are placed at distances ranging $\sim 3.12-3.36 \AA$.

\section{Conclusions}

The sodium dynamics have been studied and described for the first time in polar stuffedcristobalite $o-\mathrm{Na}_{2} \mathrm{MgSiO}_{4}$ through a complementary set of techniques (EIS, MD simulations, (VT) ${ }^{23} \mathrm{Na}$ MAS NMR and ${ }^{23} \mathrm{Na}$ EXSY NMR). $o-\mathrm{Na}_{2} \mathrm{MgSiO}_{4}$ exhibits two inequivalent $\mathrm{Na}$ sites and it should not exhibit ionic conduction on the strictly stoichiometric composition, according to molecular dynamics simulations. Yet, the synthesis route employed results partial $\mathrm{Na}$ 
volatilization $(\sim 2$ at $\%)$ that converts the material into a pure ionic conductor exhibiting moderated ionic conductivity $\left(\sim 10^{-5} \mathrm{~S} \mathrm{~cm}^{-1}\right.$ at $\left.300^{\circ} \mathrm{C}\right)$ that can be further improved by inducing additional $\mathrm{Na}$ vacancies while keeping the polar structure according to $\mathrm{Na}_{2-2 x} \mathrm{Mg}_{1-x} \mathrm{Si}_{1+x} \mathrm{O}_{4}$ formula. 1D ${ }^{23} \mathrm{Na}$ VT MAS NMR and ${ }^{23} \mathrm{Na}$ EXSY NMR clearly evidence that a sodium site exchange at $\sim \mathrm{R} T$ takes place triggering the sodium ionic conduction at higher temperatures. This work demonstrates the sodium site exchange phenomenon for first time by ${ }^{23} \mathrm{Na}$ EXSY NMR and paves the way to possible further identification of sodium ionic conductors from complex structures as 3D stuffed-cristobalite ones exhibiting multiple sites for mobile ions.

\section{AUTHOR INFORMATION}

\section{Corresponding Author}

*E-mail: kuangxj@glut.edu.cn

\section{ACKNOWLEDGMENT}

The authors thank the National Science Foundation of China (Nos. 21850410458, 22090043 and 21622101) Guangxi Natural Science Foundation (No. 2019GXNSFGA245006) as well as the CNRS (IR-RMN-THC Fr30560) for the financial support. Prof. Sangen Zhao is acknowledged for the help on SHG measurements.

\section{ASSOCIATED CONTENT}

Supporting Information. SPD diffraction refinements; SEM-EDS elemental mapping for $\mathrm{Na}_{2} \mathrm{MgSiO}_{4}$; Laboratory XRD patterns of $o-\mathrm{Na}_{2-2 x} \mathrm{Mg}_{1-x} \mathrm{Si}_{1+x} \mathrm{O}_{4}$ samples and normalized refined lattice parameters; ${ }^{29} \mathrm{Si}$ MAS NMR spectrum; Complex impedance plot at $60{ }^{\circ} \mathrm{C}$; Equivalent circuit to fit the EIS spectrum recorded at $154{ }^{\circ} \mathrm{C}$; VTXRD, DSC and unit cell evolution within 
$30-750{ }^{\circ} \mathrm{C}$ Arrhenius plot of the sodium diffusion coefficient; ${ }^{23} \mathrm{Na}$ spin-lattice relaxation times plotted against 1000/T; Structural parameters and selected interatomic distances at room temperature; Interatomic potential parameters used for the MD simulations and experimental and calculated structural parameters; Multiple-unit-cell Rietveld model description.

\section{REFERENCES}

1. Yabuuchi, N.; Kubota, K.; Dahbi, M.; Komaba, S. Research Development on Sodium-Ion Batteries. Chem. Rev. 2014, 114, 11636-11682.

2. Rosseinsky, D. R.; Mortimer, R. J. Electrochromic Systems and the Prospects for Devices. Adv. Mater. 2001, 13, 783-793.

3. Sun, J. Y.; Keplinger, C.; Whitesides, G. M.; Suo, Z. G. Ionic Skin. Adv. Mater. 2014, 26, 7608-7614.

4. Mahato, N.; Banerjee, A.; Gupta, A.; Omar, S.; Balani, K. Progress in Material Selection for Solid Oxide Fuel Cell Technology: A Review. Prog. Mater Sci. 2015, 72, 141-337.

5. Yang, X.; Fernández-Carrión, A. J.; Wang, J.; Porcher, F.; Fayon, F.; Allix, M.; Kuang, X. Cooperative Mechanisms of Oxygen Vacancy Stabilization and Migration in the Isolated Tetrahedral Anion Scheelite Structure. Nat. Commun. 2018, 9, 4484.

6. Xu, J.; Wang, J.; Rakhmatullin, A.; Ory, S.; Fernández-Carrión, A. J.; Yi, H.; Kuang, X.; Allix, M. Interstitial Oxide Ion Migration Mechanism in Aluminate Melilite $\mathrm{La}_{1+\mathrm{x}} \mathrm{Ca}_{1-\mathrm{x}} \mathrm{Al}_{3} \mathrm{O}_{7+0.5 \mathrm{x}}$ Ceramics Synthesized by Glass Crystallization. ACS Appl. Energy Mater. 2019, 2, 2878-2888. 
7. Kirchhain, H.; van Wüllen, L. Solid state NMR at very high temperatures. Prog. Nucl. Magn. Reson. Spectrosc. 2019, 114-115, 71-85.

8. Stebbins, J. F. In Modern Methods in Solid-state NMR: A Practitioner's Guide; The Royal Society of Chemistry: 2018; pp 262-288.

9. Stebbins, J. F. Dynamics in Ceramics. Science 2002, 297, 1285-1287.

10. Böhmer, R.; Storek, M.; Vogel, M. In Modern Methods in Solid-state NMR: A Practitioner's Guide; The Royal Society of Chemistry: 2018; pp 193-230.

11. Xu, Z.; Stebbins, J. F. Cation Dynamics and Diffusion in Lithium Orthosilicate - 2Dimensional Li-6 NMR. Science 1995, 270, 1332-1334.

12. Verhoeven, V. W. J.; de Schepper, I. M.; Nachtegaal, G.; Kentgens, A. P. M.; Kelder, E. M.; Schoonman, J.; Mulder, F. M. Lithium Dynamics in $\mathrm{LiMn}_{2} \mathrm{O}_{4}$ Probed Directly by TwoDimensional Li-7 NMR. Phys. Rev. Lett. 2001, 86, 4314-4317.

13. Baur, W. H.; Ohta, T.; Shannon, R. D. Structure of Magnesium Disodium Silicate $\mathrm{Na}_{2} \mathrm{MgSiO}_{4}$ and Ionic Conductivity in Tetrahedral Structures. Acta Crystallogr. B 1981, 37, $1483-1491$.

14. Shannon, R. D. Ionic Conductivity in Sodium Magnesium Silicates. Phys. Chem. Miner. 1979, 4, 139-148.

15. Withers, R. L.; Lobo, C.; Thompson, J. G.; Schmid, S.; Stranger, R. A Modulation Wave Approach to the Structural Characterization of Three New Cristobalite-Related Sodium Magnesiosilicates. Acta Crystallogr. B 1997, 53, 203-220. 
16. Kurtz, S. K.; Perry, T. T. A Powder Technique for the Evaluation of Nonlinear Optical Materials. J. Appl. Phys. 1968, 39, 3798-3813.

17. Coelho, A. A. TOPAS and TOPAS-Academic: an Optimization Program Integrating Computer Algebra and Crystallographic Objects Written in C++. J. Appl. Crystallogr. 2018, 51, 210-218.

18. Brown, I. D.; Altermatt, D. Bond - Valence Parameters Obtained from a Systematic Analysis of the Inorganic Crystal Structure Database. Acta Crystallogr. B 1985, 41, 244-247.

19. O'Keeffe, M.; Brese, N. E. Bond-Valence Parameters for Anion-Anion Bonds in Solids. Acta Crystallogr. B 1992, 48, 152-154.

20. Massiot, D.; Fayon, F.; Capron, M.; King, I.; Le Calve, S.; Alonso, B.; Durand, J. O.; Bujoli, B.; Gan, Z. H.; Hoatson, G. Modelling One- and Two-Dimensional Solid-State NMR Spectra. Magn. Reson. Chem. 2002, 40, 70-76.

21. Rakhmatullin, A.; Šimko, F.; Véron, E.; Allix, M.; Martineau-Corcos, C.; Fitch, A.; Fayon, F.; Shakhovoy, R. A.; Okhotnikov, K.; Sarou-Kanian, V.; Korenko, M.; Netriová, Z.; Polovov, I. B.; Bessada, C. X-ray DIffraction, NMR Studies, and DFT Calculations of the Room and High Temperature Structures of Rubidium Cryolite, $\mathrm{Rb}_{3} \mathrm{AlF}_{6}$. Inorg. Chem. 2020, 59, 63086318.

22. Venkatachalam, S.; Schröder, C.; Wegner, S.; Van Wüllen, L. The Structure of a Borosilicate and Phosphosilicate Glasses and its Evolution at Temperatures Above the Glass Transition Temperature: Lessons from in situ MAS NMR. Phys. Chem. Glasses-B 2014, 55, $280-$ 287. 
23. Messinger, R. J.; Ménétrier, M.; Salager, E.; Boulineau, A.; Duttine, M.; Carlier, D.; Ateba Mba, J.-M.; Croguennec, L.; Masquelier, C.; Massiot, D.; Deschamps, M. Revealing Defects in Crystalline Lithium-Ion Battery Electrodes by Solid-State NMR: Applications to $\mathrm{LiVPO}_{4} \mathrm{~F}$. Chem. Mater. 2015, 27, 5212-5221.

24. Johnson, D. Zview for Windows, Impedance/Gain Phase Graphing and Analysis Software, Scribner Associates: North Carolina, 2001.

25. Segall, M. D.; Lindan, P. J. D.; Probert, M.; Pickard, C. J.; Hasnip, P.; Clark, S. J.; Payne, M. C. First-Principles Simulation: Ideas, Illustrations and the CASTEP Code. J. Phys.: Condens. Matter 2002, 14, 2717-2744.

26. Clark, S. J.; Segall, M. D.; Pickard, C. J.; Hasnip, P. J.; Probert, M. J.; Refson, K.; Payne, M. C. First Principles Methods Using CASTEP. Z. Kyrstallogr. 2005, 220, 567-570.

27. Šimko, F.; Rakhmatullin, A.; Florian, P.; Kontrík, M.; Korenko, M.; Netriová, Z.;

Danielik, V.; Bessada, C. (Oxo)(Fluoro)-Aluminates in $\mathrm{KF}-\mathrm{Al}_{2} \mathrm{O}_{3}$ System: Thermal Stability and Structural Correlation. Inorg. Chem. 2017, 56, 13349-13359.

28. Gale, J. D. GULP: A computer program for the symmetry-adapted simulation of solids. $J$. Chem. Soc. Faraday Trans. 1997, 93, 629-637.

29. Gale, J. D.; Rohl, A. L. The General Utility Lattice Program (GULP). Mol. Simul. 2003, 29, 291-341.

30. Dick, B. G.; Overhauser, A. W. Theory of the Dielectric Constants of Alkali Halide Crystals. Phys. Rev. 1958, 112, 90-103. 
31. Jackson, R. A.; Catlow, C. R. A. Computer Simulation Studies of Zeolite Structure. Mol. Simul. 1988, 1, 207-224.

32. Heath, J.; Chen, H.; Islam, M. S. $\mathrm{MgFeSiO}_{4}$ as a Potential Cathode Material for Magnesium Batteries: Ion Diffusion Rates and Voltage Trends. J. Mater. Chem. A 2017, 5, 13161-13167.

33. Todorov, I. T.; Smith, W.; Trachenko, K.; Dove, M. T. DL_POLY_3: New Dimensions in Molecular Dynamics Simulations Via Massive Parallelism. J. Mater. Chem. 2006, 16, 19111918.

34. Berendsen, H. J. C.; Postma, J. P. M.; Gunsteren, W. F. v.; DiNola, A.; Haak, J. R. Molecular Dynamics with Coupling to an External Bath. J. Chem. Phys. 1984, 81, 3684-3690.

35. Humphrey, W.; Dalke, A.; Schulten, K. VMD: Visual Molecular Dynamics. J. Mol. Graph. 1996, 14, 33-38.

36. Róg, T.; Murzyn, K.; Hinsen, K.; Kneller, G. R. nMoldyn: A Program Package for a Neutron Scattering Oriented Analysis of Molecular Dynamics Simulations. J. Comput. Chem. 2003, 24, 657-667.

37. Shannon, R. D. Ionic Conductivity in Sodium Magnesium Silicates. Phys. Chem. Miner. 1979, 4, 139-148.

38. Nakashima, Y.; Sakamoto, W.; Maiwa, H.; Shimura, T.; Yogo, T. Lead-Free Piezoelectric (K,Na) $\mathrm{NbO}_{3}$ Thin Films Derived from Metal Alkoxide Precursors. Jpn. J. Appl. Phys. 2007, 46, L311-L313. 
39. Thompson, J. G.; Withers, R. L.; Palethorpe, S. R.; Melnitchenko, A. Cristobalite-Related Oxide Structures. J. Solid State Chem. 1998, 141, 29-49.

40. Irvine, J. T. S.; Sinclair, D. C.; West, A. R. Electroceramics: Characterization by Impedance Spectroscopy. Adv. Mater. 1990, 2, 132-138.

41. Kuang, X.; Green, M. A.; Niu, H.; Zajdel, P.; Dickinson, C.; Claridge, J. B.; Jantsky, L.; Rosseinsky, M. J. Interstitial Oxide Ion Conductivity in the Layered Tetrahedral Network Melilite Structure. Nat. Mater. 2008, 7, 498-504.

42. Li, M.; Pietrowski, M. J.; De Souza, R. A.; Zhang, H. R.; Reaney, I. M.; Cook, S. N.; Kilner, J. A.; Sinclair, D. C. A Family of Oxide Ion conductors Based on the Ferroelectric Perovskite $\mathrm{Na}_{0.5} \mathrm{Bi}_{0.5} \mathrm{TiO}_{3}$. Nat. Mater. 2014, 13, 31-35.

43. Yang, X.; Liu, S.; Lu, F.; Xu, J.; Kuang, X. Acceptor Doping and Oxygen Vacancy Migration in Layered Perovskite $\mathrm{NdBaInO}_{4}$-Based Mixed Conductors. J. Phys. Chem. C 2016, $120,6416-6426$.

44. Stebbins, J. F.; Farnan, I.; Williams, E. H.; Roux, J. Magic Angle Spinning NMR Observation of Sodium Site Exchange in Nepheline at 500 C. Phys. Chem. Miner. 1989, 16, 763-766.

45. Peet, J. R.; Widdifield, C. M.; Apperley, D. C.; Hodgkinson, P.; Johnson, M. R.; Evans, I. R. $\mathrm{Na}^{+}$Mobility in Sodium Strontium Silicate Fast Ion Conductors. Chem. Commun. 2015, 51, 17163-17165. 
46. Udovic, T. J.; Matsuo, M.; Tang, W. S.; Wu, H.; Stavila, V.; Soloninin, A. V.; Skoryunov, R. V.; Babanova, O. A.; Skripov, A. V.; Rush, J. J.; Unemoto, A.; Takamura, H.; Orimo, S.-i. Exceptional Superionic Conductivity in Disordered Sodium Decahydro-closo-decaborate. Adv. Mater. 2014, 26, 7622-7626.

47. Yamada, K.; Kumano, K.; Okuda, T. Conduction path of the Sodium ion in $\mathrm{Na}_{3} \mathrm{InCl}_{6}$ Studied by X-ray Diffraction and ${ }^{23} \mathrm{Na}$ and ${ }^{115}$ In NMR. Solid State Ion. 2005, 176, 823-829. 